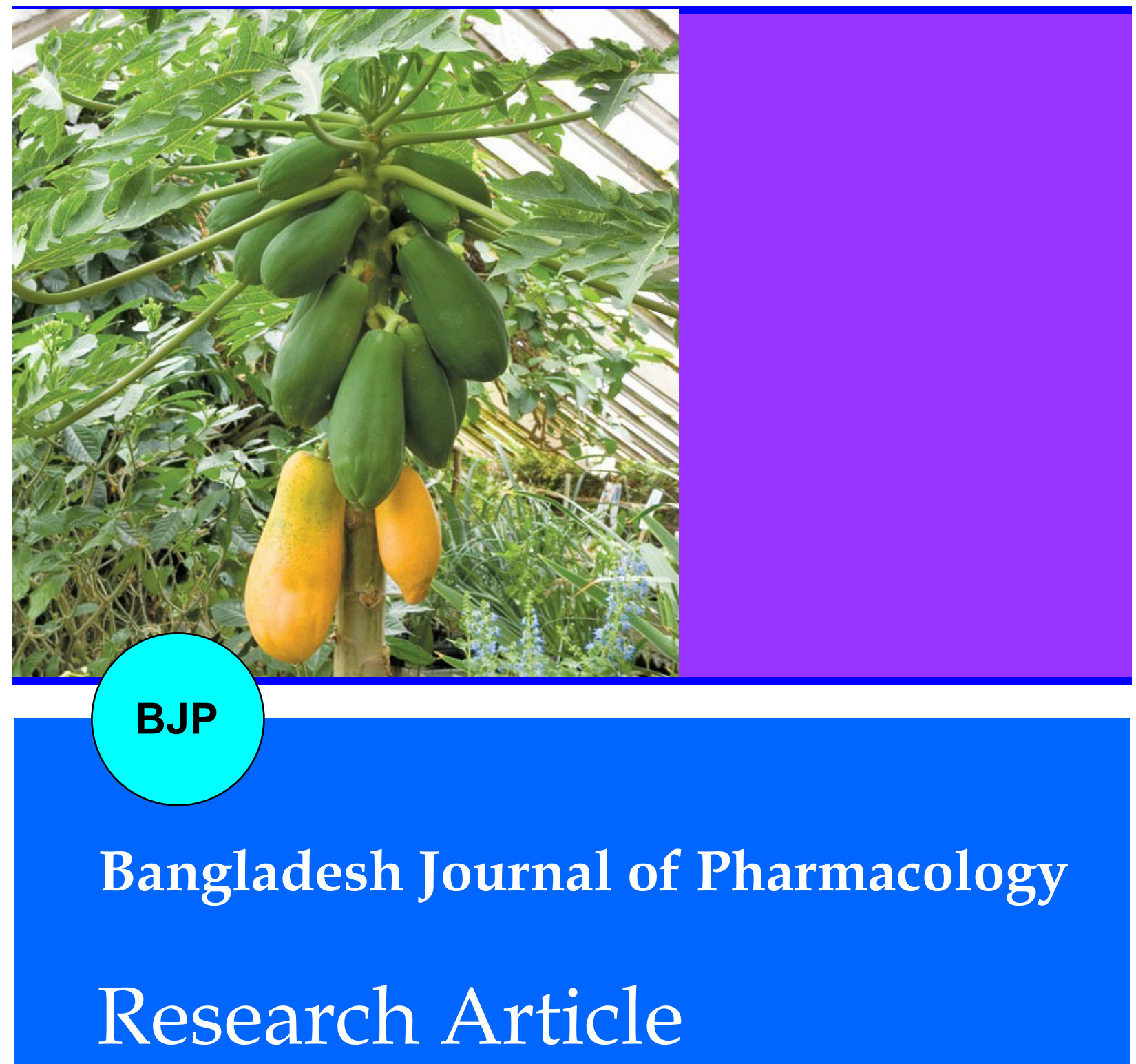

In vitro study of antiamoebic effect of methanol extract of mature seeds of Carica papaya on trophozoites of Entamoeba histolytica 


\title{
In vitro study of antiamoebic effect of methanol extract of mature seeds of Carica papaya on trophozoites of Entamoeba histolytica
}

\author{
Sujit Kumar Sarker'1, Nilufar Begum², Dinesh Mondal3, Md. Abdullah Siddique3 and \\ Mohammad A. Rashid4
}

\author{
${ }^{1}$ Department of Pharmacology and Therapeutics, Dhaka Medical College, Dhaka 1000, Bangladesh; ${ }^{2}$ Department of \\ Pharmacology and Therapeutics, Shahabuddin Medical College, Dhaka 1212, Bangladesh; ${ }^{3}$ Parasitology \\ Laboratory, ICDDR, B Dhaka 1212, Bangladesh; ${ }^{4}$ Department of Pharmaceutical Chemistry, Faculty of Pharmacy, \\ University of Dhaka 1000, Bangladesh.
}

\begin{tabular}{|c|c|}
\hline \multicolumn{2}{|l|}{ Article Info } \\
\hline & \\
\hline & \\
\hline Available Online: & \\
\hline \multicolumn{2}{|c|}{ DOI: 10.3329/bjp.v5i1.5003 } \\
\hline \multicolumn{2}{|c|}{$\begin{array}{l}\text { Cite this article: } \\
\text { Sarker SK, Begum N, Mondal D, Sid- } \\
\text { dique MA, Rashid MA. In vitro study } \\
\text { of antiamoebic effect of methano } \\
\text { extract of mature seeds of Carica papa } \\
\text { ya on trophozoites of Entamoeba histo } \\
\text { lytica. Bangladesh J Pharmacol. } 2010 \\
\text { 5: } 45-47 \text {. }\end{array}$} \\
\hline
\end{tabular}

\section{Abstract}

Antiamoebic activity of methanol extract of mature seeds of Carica papaya was tested in vitro on axenic culture of Entamoeba histolytica using metronidazole as a reference amoebicidal agent. The MIC of seed extract was $>62.5 \mu \mathrm{g} / \mathrm{mL}$ as compared to $<0.8 \mu \mathrm{g} / \mathrm{mL}$ for metronidazole. The present study suggests that the mature seeds of C. papaya have antiamoebic effect but less pronounced than metronidazole.

\section{Introduction}

A large number of populations in Bangladesh are suffered from amoebiasis caused by Entamoeba histolytica. Only limited numbers of drugs are available for the treatment of amoebiasis. Among them metronidazole is used for many years. But indiscriminate use may cause drug resistance in future (Bansal et al., 2006). To overcome this problem we have to find out more antiamoebic drugs. Plants may be a good source. The antiamoebic effect of Carica papaya (seed), Mangifera indica (stem bark) and marine sponge Haliclona exigua have been reported elsewhere (Tona et al., 1998; Calzada et al., 2006; Lakshmi et al., 2009). The minimum inhibitory concentration (MIC) values of C. papaya were conflicting. Therefore the present study was conducted to evaluate the effectiveness of mature seeds of papaya against E. histolytica, using metronidazole as a reference standard.

\section{Materials and Methods \\ Plant materials}

Dried mature seeds of C. papaya were collected from Manikgonj in November, 2006. The plants were identified at Bangladesh National Herbarium, Dhaka where a voucher specimen has been deposited (DACB accession number was 31374) for this collection.

\section{Preparation of extract}

Dried papaya seeds were first ground to a coarse powder and then methanol extract was prepared by macerating powdered seeds in methanol for a week. Then the slurry was first filtered and solvent was evaporated under reduced pressure by using a rotary evaporator. Then the extract thus obtained was stored until in vitro antiamoebic test.

\section{Culture of E. histolytica}




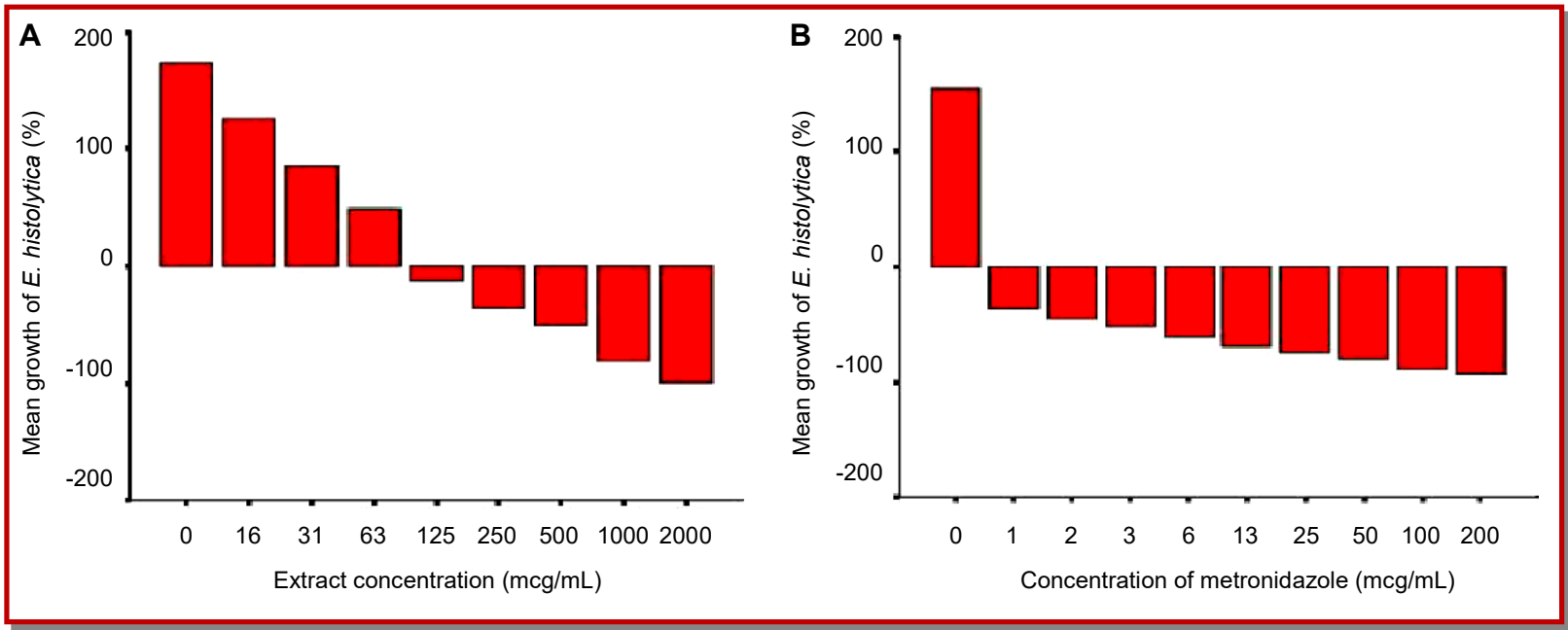

Figure 1: Mean growth of E. histolytica in presence of extract of C. papaya (A) and metronidazole (B)

DS 4868 strain of E. histolytica was used in the present study. Here, established axenic culture of E. histolytica and LYI-S-2 culture media was kindly provided by Dr. Rashidul Haque, Head of Parasitology Laboratory, ICDDR,B Dhaka.

\section{Serial dilutions}

Serial dilutions of stock solution in culture medium were conducted in 24 well culture plates. For the extract, serial dilutions were conducted to get 2000 to $15.6 \mu \mathrm{g} / \mathrm{mL}$ and for metronidazole solutions were made from 200 to $0.8 \mu \mathrm{g} / \mathrm{mL}$.

\section{Trials of the study}

Several trials were conducted for the study. Each trial included blank (only culture medium), control (culture medium and E. histolytica) and test (extract or metronidazole, culture medium and E. histolytica).

\section{Count of E. histolytica}

After incubation for 48 hours at $37^{\circ} \mathrm{C}$ viable trophozoites of E. histolytica were counted with the aid of Neubauer's cell of hemocytometer.

\section{Results}

Antiamoebic activity of mature seeds of C. papaya was investigated under different experimental conditions for determination of MIC. The MIC is considered as the gold standard for determining the antiamoebic test in vitro (Andrew, 2001). In this study MIC was defined as the lowest concentration of seed extract and metronidazole that inhibited the growth of E. histolytica after 48 hours incubation.

All the trials of C. papaya suggested that the methanol extract of mature seeds of C. papaya had antiamoebic effect on trophozoites of E. histolytica and the MIC value was $>62.5 \mu \mathrm{g} / \mathrm{mL}(\mathrm{p}<0.001)$. Figure $1 \mathrm{~A}$ shows the statistical analyses of the extract study. It shows the mean growth of E. histolytica. In this study concentrations of extract were 2000, 1000, 500, 250, 125, $62.5,31.3,15.6 \mu \mathrm{g} / \mathrm{mL}$. It was evident that the growth of organism occurred at the extract concentration of 0 to 63 $\mu \mathrm{g} / \mathrm{mL}$ where $0 \mu \mathrm{g} / \mathrm{mL}$ was the control and growth was inhibited at the extract concentration of 125 to 2,000 $\mu \mathrm{g} / \mathrm{mL}$. Therefore, the MIC was $>62.5$ but $<125 \mu \mathrm{g} / \mathrm{mL}$.

Figure 1B shows the statistical analyses of the metronidazole study. It shows the mean growth of $E$. histolytica. In this study concentrations of metronidazole were $200,100,50,25,12.5,6.3,3.1,1.6$ and $0.8 \mu \mathrm{g} / \mathrm{mL}$. It was evident that growth of organism was inhibited at all concentrations, except $0 \mu \mathrm{g} / \mathrm{mL}$ which was the control. In control there was increased count of organism compared with initial count. But growth of organism was inhibited by all the concentrations of metronidazole, which was also compared with initial count. Therefore, the MIC was $<0.8 \mu \mathrm{g} / \mathrm{mL}$.

\section{Discussion}

In this study, the methanol extract of mature seeds of $C$. papaya was tested for its antiamoebic activity. Axenic culture of E. histolytica by LYI-S-2 medium is a newer procedure, which involving gradual adaptation of the parasite to a new way of life (Clark and Diamond, 2002). During the study several trials were conducted but only few trials were accepted. Others failed due to contamination of axenic culture. For this study only non -contaminated axenic culture was used.

Previous study reported the MIC value of aqueous extract of mature seeds of C. papaya was $<7.8 \mu \mathrm{g} / \mathrm{mL}$ and that of immature seeds was $62.5 \mu \mathrm{g} / \mathrm{mL}$ and MIC 
value of metronidazole was $<2.5 \mu \mathrm{g} / \mathrm{mL}$ (Tona et al., 1998) and the $\mathrm{IC}_{50}$ value of C. papaya seeds was $153 \mu \mathrm{g} /$ $\mathrm{mL}$, while that of metronidazole was $0.04 \mu \mathrm{g} / \mathrm{mL}$ (Calzada et al., 2006).

The result of the present study is consistent with the findings observed by previous study but difference in MIC value which may be due to difference in variety of papaya seeds, full maturity of seeds, time of seed collection, extraction procedure, Strain of E. histolytica, culture media or incubation period. C. papaya contains many biologically active compounds in its different parts. Among the compound carpaine and benzylisothiocyanate found mainly in seeds (Krishna et al., 2008). Antiamoebic actvity of papaya seeds may be occured due to these compounds but further study is required for validation. From the study it was also observed that metronidazole is still sensitive to E. histolytica and exhibits greater amoebicidal activity as compared with the papaya seeds. This may be due to crude nature of the test extract. Drug resistance against metronidazole is still not established but it may develop near future so continuous study is required for herbal extracts and metronidazole.

\section{Conclusion}

The present study suggests that metronidazole is more potent than the methanol extract of C. papaya.

\section{Acknowledgement}

The authors are grateful to Dr. Rashidul Haque, Head of
Parasitology Laboratory, ICDDR,B Dhaka for providing lab facilities to carry out the research.

\section{References}

Andrews JM. Determination of minimum inhibitory concentrations. J Antimicrob Chemother. 2001; 48: 5-16.

Bansal D, Sehgal R, Chawla Y, Malla N, Mahajan RC. Multidrug resistance in amoebiasis patient. Indian J Med Res. 2006; 124: 189-94.

Calzada F, Yepez-mulia L, Aguilar A. In vitro susceptibility of Entamoeba histolytica and Giardia lamblia to plants used in Mexican traditional medicine for the treatment of gastrointestinal disorders. J Ethnopharmacol. 2006; 108: 36770.

Clark CG, Diamond LS. Methods for cultivation of luminal parasitic protists of clinical importance. Clin Microbiol Rev. 2002; 15: 329-41.

Ghani A. Carica papaya (Linn). In: Ghani A, (ed). Medicinal plants of Bangladesh with chemical constituents. $2^{\text {nd }}$ ed. Dhaka, Asiatic Society of Bangladesh, 2003, p149.

Krishna KL, Paridhavi M, Patel JA. Review on nutritional, medicinal and pharmacological properties of papaya (Carica papaya Linn.). Nat Prod Radian. 2008; 7: 364-73.

Lakshmi V, Saxena A, Mishra SK, Mishra M, Srivastava S, Ghoshal S. Antiamoebic activity of marine sponge Haliclona exigua (Krikpatrick). Bangladesh J Pharmacol. 2009; 4: 55-59.

Tona L, Kambu K, Ngimbi N, Cimanga K, Vlietinck AJ. Antiamoebic and phytochemical screening of some Congolese medicinal plants. J Ethnopharmacol. 1998; 61: 5765. 